ORIGINAL ARTICLE

\title{
Orthodontists' Attitude and Practice in the Provision of Orthodontic Treatment for Patients with Visual and Hearing Impairments
}

\author{
RABIA BILAL ${ }^{1}$, RAGHAD ALSUHAIBANI ${ }^{2}$ \\ ${ }^{1}$ Associate Professor, Department of Orthodontics, Faculty of Dentistry, Qassim University, KSA \\ ${ }^{2}$ General Dentist, E-Mail: raghad.alsuhaibani@qudent.org \\ Correspondence to Dr. Rabia Bilal, E-Mail: rabia.orthodontist@gmail.com, Phone:00966-536159613
}

\begin{abstract}
Aim: To determine the behavior and attitudes of orthodontists toward providing orthodontic care for patients with visual impairment $(\mathrm{VI})$ and hearing impairment $(\mathrm{HI})$.

Method: This cross-sectional study utilized a self-administered questionnaire that was completed by forty orthodontists. The questionnaire consisted of closed questions about past educational lectures and training in the field of special needs, as well as orthodontist's enthusiasm, confidence, and experience in the provision of treatment for patients with special needs.

A five point's Likert scale was developed and used to determine the attitude of orthodontists towards providing orthodontic treatment for patients with visual impairment (VI Scale) and hearing impairment (HI Scale).

Results: There was no statistically significant difference in the orthodontist's degrees and their country of postgraduate study in determining their general foundation and attitude towards special needs care. Furthermore, the total years of experience was found to be irrelevant. Orthodontists tended to have a more favorable attitude toward patients with $\mathrm{HI}$ than toward patients with VI. $(\mathrm{P}=0.007)$

Conclusion: People with sensory impairments cannot be considered a homogeneous group. Insight into the treatment needs for different groups of persons with disabilities is required in order to enhance treatment planning and the quality of life of these patients.

Keywords: orthodontist; orthodontic treatment, behavior; attitude; patients; visual and hearing impairments.
\end{abstract}

\section{INTRODUCTION}

Access to medical services is an indispensable right of every member of the community, and dental care is an integral component of a person's medical care. Children and adolescents with hearing and visual disabilities, a population that is viewed as high-risk for dental diseases, experience difficulty in accessing appropriate dental services. For these individuals, maintenance of good oral health is very important, as poor oral health renders functions of the oral cavity difficult, including eating, swallowing, speech, and chewing. This can ultimately result in malocclusion, compromised aesthetics, and poor general wellbeing, which add to co-morbidities ${ }^{1}$.

Oral health is often neglected because of this debilitating condition, demanding disease, or constrained access to oral health care. Dental specialists should be aware of all of the potential inabilities that they may face in clinics and, importantly, must understand how to manage them ${ }^{2}$. Orthodontic treatment for individuals with special needs has gotten generally little consideration, and the data that is accessible shows that individuals with incapacities experience issues getting orthodontic care ${ }^{3}$. While developing the functional and aesthetic components of an orthodontic treatment plan, one must consider the severity of apparently endless variety of handicapping conditions that these individuals face ${ }^{4}$. A study in India that investigated dentist's provision of care for patients with learning disabilities showed that, despite the fact that the overall attitude of dentists toward this patient population was found to be favorable, the majority $(60.7 \%)$ of participants believed that it is more stressful to treat patients with learning disabilities. Dentists likewise expressed some doubts about the capabilities and mental capacity of these patients. Specifically, dental professionals did not anticipate that they keep to maintain a similar degree of oral hygiene as non-disabled patients and were not satisfied by this population's ability to make decisions about their own health care ${ }^{5}$. Oral health improvement in a population begins with the collection of epidemiological data, which explains the requirements of the community, identify high-risk groups, plan treatment and prevention strategies, and monitor the development of the situation over years ${ }^{6}$. This study was done to determine the behavior and attitude of orthodontists in providing orthodontic care to the patients with visual and hearing impairment.

\section{MATERIALS AND METHODS}

Ethical approval was obtained from the Dental Ethics Committee of the College (Approval \#:026_Int_16/17). It was a cross sectional study in which a self-administered paper based questionnaire was developed and sent to fifty orthodontists to assess their attitudes towards $\mathrm{HI}$ and VI patients. They were explained by answering, they agreed to participate in the study and answers are classified and will be used for research purpose only. The questionnaire comprised of:

- Personal details including name, gender, qualification, university/country of orthodontic degree, and years of experience.

- Closed questions (yes/no) about past educational lectures and training in the field of special needs, as well as orthodontist's enthusiasm, confidence, and any involvement/ experience in the provision of treatment for patients with special needs.

- A five point Likert scale to determine the attitude of orthodontists towards providing orthodontic treatment 
for patients with visual impairment (VI Scale) and hearing impairment (HI Scale).

The scale consisted of four statements about patients with $\mathrm{VI}$ or $\mathrm{HI}$, including their level of interest in the appearance, their self-perception, their ability to maintain oral hygiene, and their ability to cope with orthodontic treatment. The respondent was required to give a response to each statement. Scores on singular items ranged from 1 to 5 ( $1=$ strongly agree, $2=$ agree, $3=$ undecided, $4=$ disagree, $5=$ strongly disagree), whereas higher score indicated a greater willingness to provide orthodontic care to handicapped patient population.

The questionnaire was personally given to every orthodontist to acquire an immediate response and the data were then coded and entered into the SPSS program version 17.0 (IBM Corp., Armonk, N.Y., USA) for statistical analysis.

\section{RESULTS}

Forty responses were obtained from given questionnaires. Of the respondents, 23 (57.5\%) were men and 17 (42.5\%) were women. Respondents were predominately specialists $38(95 \%)$, with $2(5 \%)$ consultants.

Subjects were approached to record the dental school from which they graduated and the number of years that they had been in dental practice. The most widely recognized nations from which the respondents obtained their orthodontic degrees were India (30\%), the Philippines $(20 \%)$, and Syria (17.5\%). Other countries that were represented included Egypt, Russia, Saudi Arabia, Jordan, Pakistan, Lebanon, France, the UK, and China. The majority of respondents had 5 years or greater experience
29 (72.5\%). Only $11(27.5 \%)$ of respondents had experience of $2-5$ years.

Orthodontist were also asked about past educational lectures and training for patients with special needs. Of the respondents, $82 \%$ had attended lectures about special needs during their postgraduate studies. The vast majority of the postgraduates from the Philippines reported that they did not attend any lectures about consideration of care for patients with special needs. At the point when orthodontists were inquired as to whether they had any experience in treating patients with special needs, the majority of orthodontists (65\%) had already treated this patient populace and were enthusiastic (70\%) and sufficiently confident $(71 \%)$ to provide treatment. The respondents recalled treating an aggregate of one-hundred and fiftyseven patients with special needs.

Results of chi-square test demonstrated no statistically significant differences in the orthodontist's degrees and their country of postgraduate study in determining their general foundation and attitude towards special needs care. Furthermore, the total years of experience was found to be irrelevant.

Next, the orthodontist's attitudes toward the provision of orthodontic care for children with $\mathrm{VI}$ or $\mathrm{HI}$ were determined. Scores on each of the four items on the scale extended somewhere in the range of 2.7 and 3.2 for patients with VI (Table I) 3.4 and 3.9 for patients with $\mathrm{HI}$ (Table II). The respondent's scores for patients with $\mathrm{VI}$ and $\mathrm{HI}$ showed variation in their values. (Table I and II). The scores were compared using a paired t-test and were shown to be significantly different $(p<0.05)$. Orthodontists tended to have a more favorable attitude toward patients with $\mathrm{HI}$ than toward patients with $\mathrm{VI}$ in their responses to each of the four statements (Table III).

Table I: VI scales to assess orthodontists's willingness to provide orthodontic care to patients with patients with VI

\begin{tabular}{|c|c|c|c|c|c|}
\hline Statement & $\begin{array}{l}\text { Strongly } \\
\text { Agree }\end{array}$ & Agree & Undecided & Disagree & $\begin{array}{l}\text { Strongly } \\
\text { Disagree }\end{array}$ \\
\hline $\begin{array}{l}\text { A. Patients with VI are not interested in their dental } \\
\text { appearance }\end{array}$ & $0(0)$ & $12(30 \%)$ & $10(25 \%)$ & $16(40 \%)$ & $2(5 \%)$ \\
\hline $\begin{array}{l}\text { B. Patients with } \mathrm{VI} \text { are not able to maintain oral hygiene } \\
\text { levels necessary for orthodontic treatment }\end{array}$ & $4(10 \%)$ & $14(35 \%)$ & $10(25 \%)$ & $11(27 \%)$ & $0(0)$ \\
\hline $\begin{array}{l}\text { C. Patients with VI are unable to cope with orthodontic } \\
\text { treatment (e.g. Fixed appliance) }\end{array}$ & $3(7.5 \%)$ & $18(45 \%)$ & $7(17.5 \%)$ & $11(27.5 \%)$ & $1(2.5 \%)$ \\
\hline $\begin{array}{l}\text { D. Patients with VI have a low self-perception } \\
\text { with regard to the severity of their malocclusion }\end{array}$ & $0(0)$ & $20(50)$ & $12(30 \%)$ & $7(17.5 \%)$ & $1(2.5 \%)$ \\
\hline
\end{tabular}

Table II: HI scales to assess orthodontists's willingness to provide orthodontic care to patients with $\mathrm{HI}$

\begin{tabular}{|l|c|c|c|c|c|}
\hline Statement & $\begin{array}{c}\text { Strongly } \\
\text { Agree }\end{array}$ & Agree & Undecided & Disagree & $\begin{array}{c}\text { Strongly } \\
\text { Disagree }\end{array}$ \\
\hline $\begin{array}{l}\text { A. Patients with HI are not interested in their dental } \\
\text { appearance }\end{array}$ & $0(0)$ & $2(5 \%)$ & $5(12.5 \%)$ & $30(70 \%)$ & $3(7.5 \%)$ \\
\hline $\begin{array}{l}\text { B. Patients with HI are not able to maintain oral hygiene } \\
\text { levels necessary for orthodontic treatment }\end{array}$ & $1(2.5 \%)$ & $3(7.5 \%)$ & $7(17.5 \%)$ & $26(65 \%)$ & $2(5 \%)$ \\
\hline $\begin{array}{l}\text { C. Patients with HI are unable to cope with orthodontic } \\
\text { treatment (e.g. Fixed appliance) }\end{array}$ & $0(0)$ & $4(10 \%)$ & $7(17.5 \%)$ & $26(65 \%)$ & $2(5 \%)$ \\
\hline $\begin{array}{l}\text { D. Patients with HI have a low self-perception with regard to } \\
\text { the severity of their malocclusion }\end{array}$ & $1(2.5 \%)$ & $6(15 \%)$ & $11(27.5 \%)$ & $18(45 \%)$ & $3(7.5 \%)$ \\
\hline
\end{tabular}

Table III: showing comparison of responses of Orthodontists for treating $\mathrm{VI}$ and $\mathrm{HI}$ patients, with significance level set at $(\mathrm{P}<0.05)$ Comparison of orthodontist's responses towards $\mathbf{P}^{\mathrm{P} \text { value }}$ treating patients with $\mathrm{VI} \& \mathrm{HI}$

\section{DISCUSSION}

A survey done by Babos and Gomes of families of children with special health care needs, revealed that $24 \%$ of their children needed dental care beyond preventive care in the 
12 months prior to the interview and $8.9 \%$ of the respondents reported that they were unable to get the required care $^{7}$. However, with appropriate behavior management interventions and pharmacologic sedation, orthodontic treatment becomes a possibility for clinicians to consider. Guardians will probably search out clinicians who can give this sort of advanced orthodontic care ${ }^{8}$. Our investigation revealed that most subjects (65\%) had treated patients with impairments with enthusiasm and confidence. The need for orthodontic treatment in children with visual and hearing impairment was previously investigated in Riyadh by Al-Sarheed et $\mathrm{al}^{9}$. Their study indicated that 20 $30 \%$ of 11-16-year-olds had an objective need for orthodontic treatment.

In addition, they expressed that dentists who obtained their undergraduate training in Europe/North America were more likely to provide orthodontic care to children with visual and hearing impairments ${ }^{9}$. Contrary to that, this investigation indicated that the area from which the orthodontists got their orthodontic degree did not determine their attitude and behavior towards providing orthodontic care for patients with special needs. The outcomes from repeated studies attest to the limited training that most dental and postdoctoral students receive for the care of patients with mental retardation and other developmental disabilities, and the restricted accessibility of required dental services for community residents with special needs ${ }^{4}$. In the same study, children with $\mathrm{HI}$ were more likely to receive dental and orthodontic treatment than children with $\mathrm{VI}^{9}$. Similarly, the responses of orthodontists in this study revealed a tendency of more favorable attitude towards patients with $\mathrm{HI}$ than patients with VI.

The fact that dentists are more willing to provide dental and orthodontic care to children with $\mathrm{HI}$ than to children with VI may be related to the dentist's perceptions of deafness and blindness. In a study involving participants from 14 countries, Ustun et al. ${ }^{10}$ reported that blindness was ranked as the fifth most disabling condition, compared to deafness, which was ranked tenth. Soto ${ }^{11}$ determined pedodontist's attitude for referral of patients with special needs for orthodontic treatment. When examined about factors to consider while referring patients with compromised systemic health, the pediatric dentists addressed that the visual capacity would be a less decisive factor for referral because the specialists believed that patients with visual disabilities can cope with orthodontic treatment.

\section{CONCLUSION}

Given that impairments are not limited to any geographic region, there is a need for the development of dental curricula to equip dentists and orthodontists with the knowledge required to treat patients with special needs.

People with sensory impairments cannot be considered a homogeneous group. We found that patients with $\mathrm{HI}$ were more likely to receive orthodontic care than patients with VI. This has implications for the planning of dental services for various groups of patients with disabilities. Further research into the treatment needs for different groups of persons with disabilities is required in order to enhance treatment planning and the quality of life of these patients.

\section{REFERENCES}

1. Francis JR, Stevenson DR, Palmer JD. Dental health and dental care requirements for young handicapped adults in Wessex. Community Dent Health. 1991; 8(2): 131-7.

2. Nunn JH, Gordon PH, Carmichael CL. Dental disease and current treatment needs in a group of physically handicapped children. Community Dent Health. 1993; 10: 389-96.

3. Al-Sarheed M, Bedi R, Alkhatib MN, Hunt N.P. Dentist's attitudes and practices toward provision of orthodontic treatment for children with visual and hearing impairments. Spec Care Dentist. 2006; 26:30-6.

4. Waldman HB, Perlman SP, Swerdloff M. Orthodontics and the population with special needs. Am J Orthod Dentofacial Orthop. 2000; 18:14-7.

5. Nagarajappa R, Tak M, Sharda AJ, Aswa K, Jalihal S, Kakatkar G. Dentists' attitude to provision of care for people with learning disabilities in Udaipur, India. Scand J Caring Sci. 2013; 27:57-62.

6. 6- Purohit B.M, Acharya S, Bhat M. Oral health status and treatment needs of children attending special schools in South India: A comparative study. Spec Care Dentist. 2010; 30: 235-41

7. Babu NC, Gomes AJ. Systemic manifestations of oral diseases. J Oral Maxillofac Pathol .2011; 15:144-47.

8. Rada R, Bakhsh HH, Evans C. Orthodontic care for the behavior-challenged special needs patient. Spec Care Dentist. 2015; 35:138-42.

9. Al-Sarheed M, Bedi R, Hunt NP. Orthodontic treatment need and self-perception of

10. 11-16-year-old Saudi Arabian children with a sensory impairment attending special schools. J Orthod. 2002; 30:3944.

11. Ustun TB, Rehm J, Chatterji S, Saxena S, Trotter R, Room R, et al. WHOMH joint Project CAR Study Group: Multipleinformant ranking of the disabling effects of different health conditions in 14 countries. Lancet. 1999; 354:111-15.

12. Soto GC. Considerations when referring patients with disabilities to orthodontic treatment. Rev Mex Ortodon. 2017; 5:148-59. 